\title{
Paraproteins with antibody activity in acute viral hepatitis and chronic autoimmune liver diseases
}

\author{
MARIA E. B. ROUX, A. FLORIN-CHRISTENSEN1, R. M. ARANA, AND \\ DEBORAH DONIACH \\ From the Department of Rheumatology and Immunology, Centro de Educacion Medica e Investigaciones \\ Clinicas, Buenos Aires, Argentina, the Department of Immunology, National Institute for Medical \\ Research, Mill Hill, London, and the Department of Immunology, Middlesex Hospital Medical School, \\ London
}

SUMMARY Of 27 patients with liver disease and cryoglobulinaemia 18 proved to have paraproteins. Six of these monoclonal immunoglobulins were shown to have antibody activity, directed to human

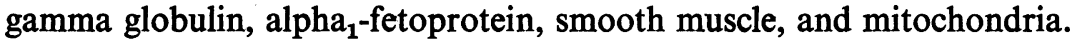

Eight of the patients suffered from acute viral hepatitis, five of whom were $\mathrm{HB} \mathrm{Ag}$ positive; in all these cases the monoclonal spikes were transient and their antibody activities were directed against IgG in two cases and alpha ${ }_{1}$-fetoprotein in one.

Seven of the patients had active chronic hepatitis and in these the paraproteinaemia persisted, though remaining quantitatively unchanged over several years. One of them had a cryoprecipitable monoclonal smooth muscle antibody. Three patients had primary biliary cirrhosis and in two of them monoclonal IgM mitochondrial antibodies were demonstrated.

In three out of the 18 cases there was a double M-component.

Since these monoclonal antibodies are directed to autoantigens not unlike the polyclonal ones usually seen in autoimmune hepatic diseases, it is suggested that the factor which triggers the uncontrolled plasma cell proliferation to produce paraproteins must meet cells from an already expanding clone.

Monoclonal proteins are increasingly reported in the absence of overt myeloma or Waldenström's macroglobulinaemia and are considered to result from the uncontrolled clonal proliferation of plasma cells. Antibody activities have been recognized in these homogeneous immunoglobulins and their study is of particular interest.

The purpose of this paper is to report the investigations performed on the sera of patients with acute viral hepatitis and chronic hepatic autoimmune disorders, ie, active chronic hepatitis and primary biliary cirrhosis.

The presence of paraproteins in cirrhosis is well documented (Michaux and Heremans, 1969; Zawadzki and Edwards, 1970, 1972), but their occurrence in acute hepatitis has only been mentioned on a few occasions (Waldenström, 1961; Osserman and

${ }^{1}$ Reprint requests to Dr A. Florin-Christensen, Department of Immunology, Middlesex Hospital Medical School, London W1P 9PG.

Received for publication 8 February 1974.
Takatsuki, 1963; Seligmann, Danon, and Clauvel, 1971). Furthermore, antibody activities in the isolated M-components, including those directed to self antigens such as smooth muscle or mitochondria and the coexistence of two paraproteins in the same serum, although well recognized in myeloma and Waldenström's macroglobulinaemia, have not been previously reported in hepatic disease.

\section{Materials and Methods}

Of a group of 27 patients with acute viral hepatitis and chronic liver diseases selected on the basis of cryoglobulinaemia in a previous study (FlorinChristensen, Roux, and Arana, 1974), 18 showed an abnormal electrophoretic pattern suggestive of paraproteinaemia. Eight of these patients had acute viral hepatitis, five of them with positive HB Ag. Seven had clinical, biochemical, and histological evidence of active chronic hepatitis and three of primary biliary cirrhosis. HB Ag was not detected 
in either of these groups. Blood was obtained by venepuncture and allowed to clot at $37^{\circ} \mathrm{C}$. LE cell tests were performed according to Hargraves (1954). All sera were submitted to paper electrophoresis and then stored at $-20^{\circ} \mathrm{C}$ until tested, except for a small aliquot which was kept at $4^{\circ} \mathrm{C}$ for the detection of cryoglobulins. Electrophoresis in gels containing $1.5 \mathrm{~g}$ agar (Noble Difco) per $100 \mathrm{ml} 0.1 \mathrm{M}$ veronal buffer (pH 8.2) was performed on an LKB apparatus employing micromethods. Immunoelectrophoresis was done according to Scheidegger (1955).

Antisera to whole human serum and plasma and to IgG and IgA were prepared in the laboratory by immunizing rabbits. For this purpose IgG was obtained from pooled normal sera by ion-exchange chromatography on DEAE-cellulose, and IgA from myeloma sera purified by gel filtration on Sephadex G200 columns and/or ion-exchange chromatography.

Rabbit antihuman IgM, IgD, and IgE and antikappa and -lambda chains were obtained commercially (Hyland). Antisera to gamma, alpha, mu, delta, and epsilon chains were rendered monospecific by absorption with purified immunoglobulins of another class. Antisera to kappa and lambda chains were absorbed with myeloma proteins known to belong to the opposite type.

Isolation of homogeneous proteins was performed by several techniques. IgM was isolated from euglobulin fractions by gel chromatography on Sephadex G200 columns $(100 \times 2.5 \mathrm{~cm})$ with $0.1 \mathrm{M}$ Tris-HC1/1 M NaCl buffer ( $\mathrm{pH} 8.0$ ). IgG was isolated and purified by chromatography on DEAEcellulose using a sodium phosphate buffer ( $\mathrm{pH} \mathrm{8 \cdot 0)}$. For IgA, pseudoglobulin fractions were employed and chromatographed on DEAE-cellulose columns. The initial buffer was $5 \mathrm{mM}$ sodium phosphate and, after IgG elution, a linear gradient was applied up to $0 \cdot 1 \mathrm{M}$. Fractions of $3 \mathrm{ml}$ were collected and concentrated by dialysis against polyvinylpyrrolidone in $0.14 \mathrm{M} \mathrm{NaCl}$. Protein concentrations were estimated by the biuret (Weichselbaum, 1946) or micro-Kjeldahl (Kabat and Mayer, 1964) methods.

Antibodies to human gamma globulin were detected by the latex fixation test according to Singer and Plotz (1956). Antiglobulins to heterologous gamma globulin were looked for by means of the sensitized sheep cell agglutination test as described in the WHO Manual of Autoimmune Serology (Roitt and Doniach, 1969).

Antibodies to nuclei, liver cytoplasm, gastric parietal cells, smooth muscle, renal tubules, and glomeruli were detected by immunofluorescence (Hamard, Cannat, and Seligmann, 1964; Roitt and Doniach, 1969). Cryostat sections $(4 \mu \mathrm{m})$ of mouse liver, kidney, and stomach were used as a substrate. In some tests human thyroid and stomach were also employed. Antiserum to human gamma globulin (IgG, IgM, and $\operatorname{IgA}$ ) was prepared in a goat and labelled with $12.5 \mu \mathrm{g}$ of fluorescein isothiocyanate per $\mathrm{mg}$ protein (Nairn, 1968). The protein: fluoroscein ratio was $1: 5$ and the labelled antiserum was used at a 1:8 dilution according to standardization. FITC-conjugated antihuman C3 was obtained commercially (Miles Laboratories).

Antibodies to native DNA and single stranded, heat-denatured DNA and to a saline-soluble calf thymus extract (Tan and Kunkel, 1966) were detected by complement-fixation and precipitin tests (Cannat, Arana, and Seligmann, 1967). The presence of $\mathrm{HB} \mathrm{Ag}$ and $\mathrm{HB} \mathrm{Ab}$ was established by double diffusion in agar and by immunoelectrophoresis. Reference sera for HB Ag and HB Ab were at first provided by Austragen Laboratories and later by Academia Nacional de Medicina, Buenos Aires, from polytransfused haemophiliac patients. When looking for $\mathrm{HB} \mathrm{Ab}, \mathrm{HB}$ Ag-positive sera were pooled in order to test patients' sera against a wider number of HB subtypes.

Alpha 1 fetoprotein $\left(\alpha_{1}\right.$ FP) and anti- $\alpha_{1}$ FP were looked for by double diffusion in agar and agarose gels. Immunoelectroosmophoresis was also used, employing gels containing $0.85 \mathrm{~g}$ agarose per 100 $\mathrm{ml} 50 \mathrm{mM}$ veronal buffer ( $\mathrm{pH} \mathrm{8.2)}$ as described previously (Florin-Christensen and Arana, 1973). Single radial immunodiffusion was used to look for small amounts of $\alpha_{1}$ FP in the cryoprecipitates (Mancini, Carbonara, and Heremans, 1965). Reference $\alpha_{1}$ FP serum and antiserum were obtained commercially (Hoechst Laboratories), and later prepared in the laboratory by immunizing rabbits with the antigen obtained from foetuses of 14 to 16 weeks' gestation.

Antigenic analyses were done according to Ouchterlony (1953) using gels with $1 \mathrm{~g}$ agar per 100 $\mathrm{ml}$ phosphate-buffered saline (pH 7-2).

Detection of Bence Jones proteins was done at pH 6. Immunoelectrophoretic analysis was performed on 100 -fold concentrates of urine.

\section{Results}

The paraproteins found in the 18 patients are shown in table I. Of the eight patients with acute viral hepatitis three had an M-component of the IgM class, four had an IgG paraprotein, and one had an IgMK, free kappa chains, and a cathodic bifurcation of the IgG precipitin arc, consistent with gamma chains devoid of light chains (figure). The spikes were all small and could not be accurately quantitated. They were first detected in the second week of illness and disappeared on recovery, between two and three months after onset. 


\begin{tabular}{llll}
\hline Patient No. & Diagnosis & HB Ag & Paraprotein(s) \\
\hline 1 & Acute viral hepatitis & - & IgMK \\
2 & Acute viral hepatitis & - & IgML \\
3 & Acute viral hepatitis & IgGL \\
4 & Acute viral hepatitis & IgGK \\
5 & Acute viral hepatitis & - & IgGL \\
6 & Acute viral hepatitis & IgMK, IgGK, free \\
& & gamma and \\
& & kappa \\
7 & Acute viral hepatitis & IgMK \\
8 & Acute viral hepatitis + & IgGK \\
9 & Active chronic hepatitis - & IgMK \\
10 & Active chronic hepatitis - & IgAK \\
11 & Active chronic hepatitis - & IgGK, IgM \\
12 & Active chronic hepatitis - & IgGL \\
13 & Active chronic hepatitis - & IgM \\
14 & Active chronic hepatitis - & IgAL \\
15 & Active chronic hepatitis - & IgMK \\
16 & Primary biliary cirrhosis - & IgMK \\
17 & Primary biliary cirrhosis & IgMK \\
18 & and diabetes mellitus - & IgMK, IgGK, free \\
& Primary biliary cirrhosis - & gamma and \\
& & kappa \\
\hline
\end{tabular}

Table I Class and type of monoclonal immunoglobulins and $\mathrm{HB}$ Ag status of 18 patients with liver disorders and cryoglobulinaemia

${ }^{1} \mathrm{~K}=$ type of immunoglobulin bearing kappa light chains, $\mathbf{L}=$ type of immunoglobulin bearing lambda light chains ${ }^{3}$ Not typed.

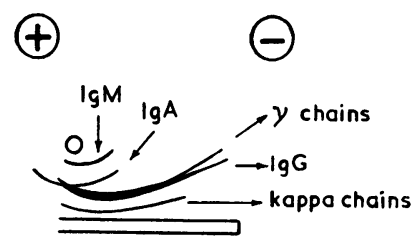

A

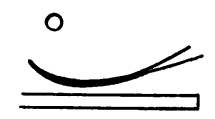

B

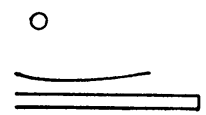

C
Fig Diagram of immunoelectrophoretic analysis of serum from patient no. 6 (acute viral hepatitis) demonstrating the presence of IgGK paraprotein and free gamma and kappa chains. Troughs contained: $A$, antiwhole human serum; $B$, antihuman IgG; $C$, antihuman lambda chains; $D$, antikappa chains.

Two of the seven patients with active chronic hepatitis showed IgM paraproteinaemia. Two had monoclonal IgA and one had an IgG M-component. The remaining case presented two paraproteins, identified as IgG and IgM. Here again the spikes were generally small but they were constantly detected over a follow-up period of up to three years, during which they did not increase significantly.

All three patients with primary biliary cirrhosis had IgMK paraproteins. One of them showed, in addition, a second spike (IgGK) and circulating free gamma and kappa chains, with an immunoelectrophoretic appearance similar to that in the figure. In two cases of primary biliary cirrhosis, the monoclonal spikes were small but in the third patient, who also had free heavy and light chains in the serum, the paraproteinaemia was more pronounced and there was a kappa Bence Jones proteinuria. In this patient, as also in the other cases of primary biliary cirrhosis, the condition did not progress to overt myelomatosis and the paraproteins remained unchanged for follow-up periods of up to four years. Marrow aspirations carried out in some of the active chronic hepatitis and all three patients with primary biliary cirrhosis, showed no significant increase in plasma cells or abnormal forms.

All the sera were tested for autoantibodies and, whenever possible the M-components were isolated by chromatography and tested in the same way. The results are shown in table II. It can be seen that IgMK from two patients with acute viral hepatitis reacted with human gamma globulin down to concentrations of 1.5 and $6.2 \mu \mathrm{g} / \mathrm{ml}$, both these patients having a mixed cryoglobulinaemia. The third case of acute viral hepatitis IgMK proved to be an antibody to $\alpha_{1}$ FP forming cold precipitable complexes. Only one of the seven paraproteins from patients with active chronic hepatitis showed antibody activity; this was an IgGK reactive with smooth muscle by immunofluorescence down to a concentration of $\mathbf{5 0}$ $\mu \mathrm{g} / \mathrm{ml}$. This paraprotein was also the sole component identified in the cryoprecipitate.

IgMK from two patients with primary biliary cirrhosis were responsible for the antimitochondrial activity of the sera from which they were derived. Fluorescent staining of distal renal tubules and gastric parietal cells with the paraprotein was positive down to concentrations of 20 and $100 \mu \mathrm{g} / \mathrm{ml}$ respectively. Both monoclonal antibodies fixed complement with the same staining pattern. With whole serum the reaction was positive in each case using anti-IgM and antikappa conjugates and negative with anti-IgG-IgA and -lambda. After chromatography of the sera only the IgM gave mitochondrial fluorescence and this could be abolished after pretreatment of the fractions with anti-IgM and antikappa, but not with anti-IgG, -IgA, or -lambda. The antibody specificity of the paraproteins was further confirmed by absorption of the mitochondrial 


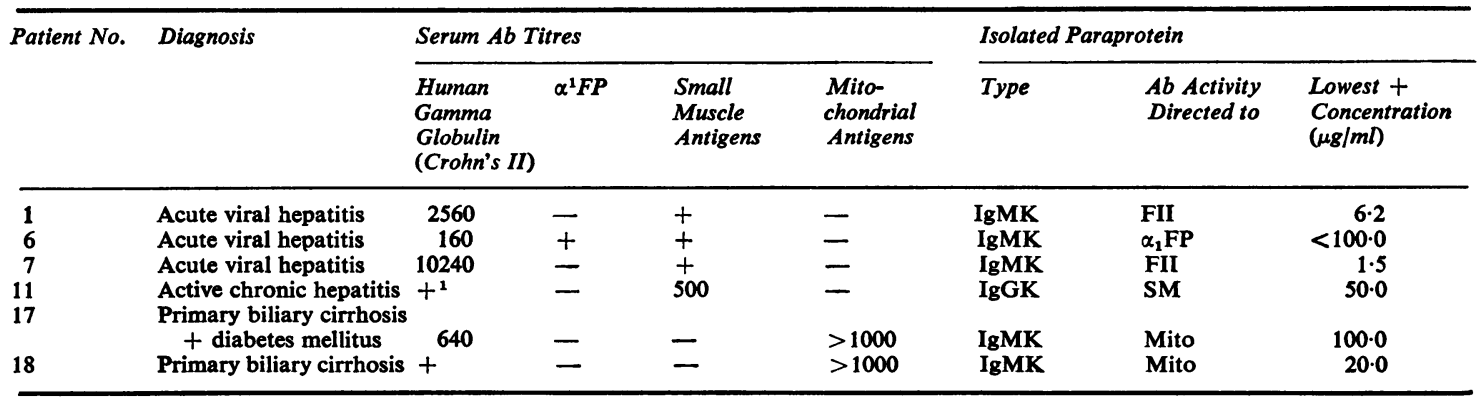

Table II Autoantibody activities in serum and isolated paraproteins of six patients with liver disease and cryoglobulinaemia

Not titred

fluorescence with mitonchondria-rich tissue fractions (Roitt and Doniach, 1969). It is of interest that the cryoprecipitates in these two cases both contained IgM and IgG and both had antiglobulin activity, but only one showed antimitonchondrial specificity. Alpha 1 FP was found in the cryoprecipitates of three patients with acute viral hepatitis and in one case of active chronic hepatitis. Antibodies to $\alpha_{1}$ FP were found in two patients with acute viral hepatitis.

The Bence Jones protein in case 18 was present in small quantities and concentrates from 3 litres of urine were necessary to establish that it was of kappa type.

\section{Discussion}

The patients described in the present study were highly selected since a cryoglobulinaemia of more than $100 \mathrm{mg} / 100 \mathrm{ml}$ occurred in less than $1 \%$ of sera tested. However it was surprising to find paraproteins in as many as two-thirds of these patients. The autoantibody activities of the sera were typical of those usually found in these diseases (Doniach et al, 1966), ie, smooth muscle antigen and antiglobulins were present in the cases of acute viral hepatitis; the patients with active chronic hepatitis had ANA, antiglobulins, smooth muscle antigens, antibodies to heat-denatured DNA in two cases, and microsomal antibodies directed primarily against liver and kidney (Rizzetto, Swana, and Doniach, 1973) in two others. The patients with primary biliary cirrhosis had high titre mitochondrial antibodies and two also had antiglobulins, as reported more fully in the cryoglobulin study (FlorinChristensen et al, 1974).

Some of the paraproteins possessed antibody activities which were found in whole sera. Followup studies showed that all three phenomena, ie, antibodies, paraproteinaemia, and cryoprecipitation, were of a transient nature in acute viral hepatitis while they appeared to be constant in active chronic hepatitis and primary biliary cirrhosis.

The finding of $\alpha_{1}$ FP in certain cryoprecipitates led to the search for antibodies to this protein (Florin-Christensen and Arana, 1973). These were found in two patients positive for $\mathrm{HB}$ Ag. In one case the anti $\alpha_{1}$ FP specificity was confined to the IgMK paraprotein, while in the other the response was polyclonal.

Diclonal spikes are known to occur in lymphoproliferative disorders but have not been found so far in acute viral hepatitis or autoimmune liver diseases. When present, they usually share a common type of light chain (Natvig and Kunkel, 1973) and this is probably true of our three cases with diclonal spikes.

The presence of free heavy and light chains is not uncommon in plasma cell malignancies and in primary amyloidosis (Osserman, Takatsuki, and Talal, 1964) but has not been previously reported in the present context. These incomplete immunoglobulins could result from a disturbance of synthesis in the affected clone(s) as postulated for myeloma, but the possibility cannot be excluded that normal immunoglobulin molecules undergo enzymatic proteolysis in the serum.

The fact that all these patients were selected for their cryoglobulinaemia probably explains why the six cases with monoclonal antibodies had antiglobulins, since it is now known that antigamma globulin factors are produced in response to circulating immune complexes. Antiglobulins are also the commonest autoantibody activity found in monoclonal proteins whether benign or malignant. It must be supposed that the factor which triggers the uncontrolled proliferation of a B cell to produce monoclonal proteins is more likely to meet with cells from an already expanded or expanding clone. In acute viral hepatitis, the transient nature of the 
autoantibodies and of the uncontrolled clonal proliferation suggest that both are directly related to the virus. In chronic autoimmune liver disorders such as active chronic hepatitis or primary biliary cirrhosis the initiating cause is unknown, but the persistent stimulus to autoantibody formation probably causes a similar selection of an already expanded clonesecreting smooth muscle antibodies or ANA in the case of active chronic hepatitis and mitochondrial antibodies in primary biliary cirrhosis as likely candidates for paraprotein synthesis.

Antibody activity to self antigens has been found in myeloma proteins Wager, Rasanen, Haltia, and Wasastjerna (1971) studied two myeloma proteins, one IgA and one IgM with smooth muscle antibody activity and a further IgG myeloma with antithyroglobulin activity. However the most commonly detected antibody activities in myeloma proteins are those directed against streptococcal and staphylococcal antigens, which again suggests that the trigger for malignant proliferation affects clones that are likely to be expanded since these organisms constantly stimulate immune responses. The unique physicochemical properties of cryoprecipitates make it possible to isolate immune complexes. In the case of cryoglobulins with autoantibody activity, particularly if the antibody is monoclonal, there is a possibility of isolating all the constituents. In mixed cryoglobulins with antiglobulin activity this has been achieved. In addition to IgG and anti-IgG antiglobulin, some systemic lupus erythematosus sera show DNA in the cryoprecipitate (Bluestone, Golberg, Cracchiolo, and. Barnett, 1970; Arana, Roux, Garcia Morteo, and Florin-Christensen, 1971), and although the source of this DNA could be foreign, it is clear that it constitutes the primary antigen in the soluble complexes which then evoke the antiglobulin response.

In the case of mitochondrial and smooth muscle reaction, the antigens have not so far been demonstrated in the cryoprecipitates, and a detailed analysis of such cryoprecipitates will make it possible to find out whether the antigens are normal body constituents or if they are in some way modified by a hypothetical infective agent.

We thank Miss Lucy Gaggero, Miss Coca Casanova, and Miss Louise Fernandez for their skilled technical assistance. We are indebted to Miss Jean Richardson for help with the manuscript. This work was partly supported by grants from CEMIC, ADAR, and the Cossio Foundation.

References

Arana, R. M., Roux, M. E. B., Garcia Morteo, O., and FlorinChristensen, A. (1971). Crioglobulinas en enfermedades del tejido conectivo. Medicina B. Aires, 31, 323-334.
Bluestone, R. M., Golberg, L. S., Cracchiolo, A., III, and Barnett, E. C. V. (1970). Detection and characterization of DNA in mixed IgG-IgM cryoglobulins. Int. Arch. Allergy, 39, 16-26.

Cannat, A., Arana, R. M., and Seligmann, M. (1967). Intérêt clinique et modalites pratiques de la recherche d'anticorps anti-acide desoxyribonucléique (DNA) natif et dénaturé. Rev. franc. Etud. clin. biol., 12, 1015-1020.

Doniach, D., Roitt, I. M., Walker, J. G., and Sherlock, S. (1966) Tissue antibodies in primary biliary cirrhosis, active chronic (lupoid) hepatitis, cryptogenic cirrhosis and other liver diseases and their clinical implications. Clin. exp. Immunol., 1, 237-262.

Florin-Christensen, A., and Arana, R. M. (1973). Alpha, fetoprotein and antialpha; fetoprotein in acute viral hepatitis. Brit. med. $J ., 2,94-95$.

Florin-Christensen, A., Roux, M. E. B., and Arana, R. M. (1974). Cryoglobulins in acute viral hepatitis and chronic autoimmune liver diseases. Clin. exp. Immunol., 16, 599-606.

Hamard, M., Cannat, A., and Seligmann, M. (1964). La recherche d'anticorps anti-nucléaires par immunofluorescence étude de 1430 sérums). Rev. frans. Etude clin. biol., 9, 716-728.

Hargraves, M. M. (1954). The LE cell phenomena. Advanc. intern. Med., 6, 133-160.

Kabat, E. A., and Mayer, M. M. (1964). Experimental Immunochemistry, 2nd ed., pp. 476-559. Thomas, Springfield, Illinois.

Mancini, G., Carbonara, A. O., and Heremans, J. F. (1965). Immunochemical quantitation of antigens by single radial immunodiffusion. Immunochemistry, 2, 235-254.

Michaux, J. L., and Heremans, J. F. (1969). Thirty cases of monoclonal immunoglobulin disorders other than myeloma and macroglobulinaemia : a classification of diseases associated with the production of monoclonal-type immunoglobulins. Amer. J. Med., 46, 562-579.

Nairn, R. C. (1968). Standardization in immunofluorescence. Clin. exp. Immunol., 3, 465-476.

Natvig, J. B., and Kunkel, H. G. (1973). Human immunoglobulins: classes, subclasses, genetic variants and idiotypes. Advanc. Immunol., 16, 1-59.

Osserman, E. F., and Takatsuki, K. (1963). The plasma proteins in liver disease. Med. Clin. N. Amer., 47, 679-710.

Osserman, E. F., Takatsuki, K., and Talal, N. (1964).Multiple mycloma I. The pathogenesis of 'amyloidosis'. Studies of the role of abnormal gamma globulins and gamma globulin fragments of the Bence-Jones type in the pathogenesis of 'primary' and 'secondary' amyloidosis and the 'amyloidosis' associated with plasma cell myeloma. Sem. Hemat., 1, 3-85.

Ouchterlony, O. (1953). Antigen-antibody reactions in gels. IV. Types of reactions in coordinated systems of diffusion. Acta path. microbiol. scand., 32, 231-240.

Rizzetto, M., Swana, G., and Doniach, D. (1973). Microsomal antibodies in active chronic hepatitis and other disorders. Clin. exp. Immunol., 15, 331-344.

Roitt, I. M., and Doniach, D. (1969). WHO Manual of Autoimmune Serology. World Health Organization, Geneva.

Scheidegger, J. J. (1955). Une micro-methode de l'immunoelectrophorese. Int. Arch. Allergy, 7, 103-110.

Seligmann, M., Danon, F., and Clauvel, J. O. (1971). Natural history of monoclonal immunoglobulins. Brit. med. J., 2, 321-322.

Singer, J. M., and Plotz, C. M. (1956). The latex fixation test. I. Application to the serological diagnosis of rheumatoid arthritis. Amer. J. Med., 21, 888-892.

Tan, E. M., and Kunkel, H. G., (1966) Characteristics of a soluble nuclear antigen precipitating with sera of patients with systemic lupus erythematosus. J. Immun., 90, 464,

Wager, O., Rasanen, J. A., Haltia, K., and Wasastjerna, C. (1971). M-components with antibody activity. Anti-smooth muscle, anti-thyroglobulin and anti-streptolysin $\mathbf{0}$ activity in five $\mathrm{M}$ component sera. Ann. clin. Res., 3, 86-97.

Waldenstrom, J. (1961). Studies on conditions associated with disturbed gamma globulin formation (Gammopathies). The Harvey Lectures, 56, 211-231.

Weichselbaum, T. E. (1946). An accurate and rapid method for the determination of proteins in small amounts of blood serum and plasma. Amer. J. clin. Path., 16, Tect. Sec., 40-49.

Zawadzki, Z. A., and Edwards, G. A. (1970). Dysimmunoglobulinemia associated with hepatobiliary disorders. Amer. J. Med., 48, 196-202.

Zawadzki, Z. A., and Edwards, G. A. (1972). Nonmyelomatous monoclonal immunoglobulinemia. In Progress in Clinical Immunology, edited by R. S. Schwartz, vol. 1, pp. 105-156. Grune and Stratton, New York. 